\title{
XMaS Scientist Experience: Promoting Careers for Women in Science
}

\author{
Kayleigh Lampard ${ }^{1}$ \\ University of Warwick, U.K. \\ E-mail: kayleigh.lampard@warwick.ac.uk
}

XMaS ran a project taking 14 female Physics students, aged 16-17 years, to Grenoble, France in April 2015. They visited the EPN Campus where they were introduced to possible science careers at such research facilities, as well as introducing them to the inspirational scientists working there. As a result of the trip, the students were truly inspired, their perceptions and stereotypes of people working in STEM careers were changed.

The European Physical Society Conference on High Energy Physics 22-29 July 2015

Vienna, Austria

\footnotetext{
${ }^{1}$ Speaker
} 